\title{
Domino heart transplant following heart-lung transplantation: a systematic review and meta-analysis
}

\author{
Elizabeth J. Maynes ${ }^{1}$, Thomas J. O'Malley ${ }^{1}$, Melissa A. Austin ${ }^{1}$, Avijit K. Deb ${ }^{2}$, Jae Hwan Choi ${ }^{1}$, \\ Matthew P. Weber ${ }^{1}$, Asghar Khaghani ${ }^{3}$, H. Todd Massey ${ }^{1}$, Richard C. Daly ${ }^{4}$, Vakhtang Tchantchaleishvili ${ }^{1}$ \\ ${ }^{1}$ Division of Cardiac Surgery, Thomas Jefferson University, Philadelphia, PA, USA; ${ }^{2}$ Philadelphia College of Osteopathic Medicine, Philadelphia, \\ PA, USA; ${ }^{3}$ Spectrum Health, Grand Rapids, MI, USA; ${ }^{4}$ Mayo Clinic, Rochester, MN, USA \\ Correspondence to: Vakhtang Tchantchaleishvili, MD. Assistant Professor of Surgery, Division of Cardiac Surgery, Sidney Kimmel Medical College, \\ Thomas Jefferson University, 1025 Walnut St, Suite 607, Philadelphia, PA 19107, USA. Email: Vakhtang.Tchantchaleishvili@jefferson.edu.
}

\begin{abstract}
Background: The domino-donor operation occurs when a "conditioned" heart from the heart-lung transplant (HLT) recipient is transplanted into a separate heart transplant (HT) recipient. The purpose of this systematic review was to investigate the indications and outcomes associated with the domino procedure. Methods: An electronic search was performed to identify all prospective and retrospective studies on the domino procedure in the English literature. Eight studies reported 183 HLT recipients and 263 HT recipients who were included in the final analysis.

Results: HLT indications included cystic fibrosis in 58\% (95\% CI: 27-84\%) of recipients, primary pulmonary hypertension $(\mathrm{PPH})$ in $17 \%$ (95\% CI: 12-24\%), bronchiectasis in 5\% (95\% CI: 3-10\%), emphysema in 5\% (95\% CI: 0-45\%), and Eisenmenger's syndrome in 4\% (95\% CI: 2-8\%). HT indications included ischemic heart disease in 40\% (95\% CI: 33-47\%), non-ischemic disease in 39\% (95\% CI: 25-56\%), and re-transplantation in $10 \%$ (95\% CI: 1-59\%). The pooled mean pulmonary vascular resistance (PVR) in HT recipients was 3.05 Woods units (95\% CI: 0.14-5.95). The overall mortality in the HLT group was $28 \%$ (95\% CI: $18-41 \%$ ) at an average follow-up of 15.68 months (95\% CI: 0.82-30.54), and 35\% (95\% CI: $17-58 \%)$ in the HT group at an average follow-up of 37.26 months (95\% CI: 6.68-67.84). Freedom from rejection in $\mathrm{HT}$ was $94 \%$ (95\% CI: 75-99\%) at 1 month, $77 \%$ (95\% CI: 30-96\%) at 6 months, and $41 \%$ (95\% CI: $33-50 \%)$ at 1 year.

Conclusions: The domino procedure appears to be a viable option in properly selected patients that can be performed safely with acceptable outcomes.
\end{abstract}

Keywords: Domino procedure; heart-lung transplant (HLT); multiple-organ transplant

Submitted Nov 04, 2019. Accepted for publication Dec 12, 2019.

doi: 10.21037/acs.2019.12.02

View this article at: http://dx.doi.org/10.21037/acs.2019.12.02

\section{Introduction}

The domino procedure, a surgical strategy used in the setting of multiple-organ transplants, is characterized by viable organ procurement from an organ transplant recipient that is subsequently utilized in another suitable recipient.

The technique has been performed successfully in the setting of heart-kidney, heart-lung, and heartliver transplants and is considered a strategy capable of incrementally increasing the donor organ pool. The procedure could therefore contribute to resource allocation strategies in today's era of substantial organ shortages when any increase in available organs is beneficial. According to the United Network for Organ Sharing (UNOS) database, 18 patients on average die each day waiting for an organ (1). The first reported domino procedure involving a heart-lung transplant (HLT) was performed in London's Harefield Hospital by Dr. Magdi Yacoub in 1987 (2). HLT, at the time, was considered an alternative option to double lung transplantation (DLT) and in particular en bloc DLT. Due 
to challenges inherent in DLT techniques during this era, these procedures were often complicated by necrosis or even dehiscence of the bronchial anastomosis (3). Since that time, domino procedures have been performed at HLT centers throughout the US and UK. Thus far, a large majority of HLT have resulted in domino donor heart transplant (HT). One study noted that $85 \%$ of their HLT produced a viable donor organ suitable for subsequent domino transplant (4).

Some of the known advantages of live donor transplants associated with domino procedures include pre-transplant conditioning of a donor organ that may be well-adapted for domino-donor recipients who often have lung disease associated with right heart dysfunction (5). Further, since the domino donor is live donor, certain adverse physiologic changes are avoided. These advantages have been shown to have protective post-operative effects in the HT recipients of living donor. However, despite the theoretical advantages at both the patient level and organ-availability level, over the past 20 years there has been a decrease in HLT (and associated domino-donor heart procedures) due to the emergence of the double lung transplant (DLT) and bilateral sequential single lung transplant (BSSLT). The decrease in HLT has been met with some controversy by practitioners. Opponents of HLT for diseases such as cystic fibrosis argue that removing the heart-lung block in lung transplant recipients may be unnecessary in those who simply need new lungs (as studies have shown similar outcomes in patients receiving DLT vs. HLT) $(6,7)$ and that HLT does not provide an organ supply advantage as HL blocks are often discarded.

However, proponents of HLT with a subsequent domino HT see great potential for increasing available organ supply through implementation of organ allocation strategies surrounding this procedure for patients in which HLTs are already indicated (4). Therefore, the current status of domino heart operations is met with some uncertainty.

HLT are still the definitive treatment for patients with certain congenital heart disorders and for those with Eisenmenger's syndrome; therefore, the use of a domino transplant protocol with HLT may increase organ availability and still benefit a large number of patients. This is especially the case for younger patients born with primary pulmonary hypertension (PPH). A domino transplant following HLT involving the youngest live donor occurred approximately 15 years ago between a 3 -month-old heart-lung recipient and a 3-month-old heart recipient (8). The ability of modern clinicians to correctly and surgically treat certain congenital heart disorders before transplant allows hearts to be available for a domino transplant compared to the past.

Despite continuously evolving lung transplant techniques, the HLT remains relevant for patients with specific indications, such as PHTN and Eisenmenger's syndrome. Therefore, the domino procedure has the potential to optimize organ allocation and is a potential strategy to combat the ever-growing HT waiting list. Studies suggest that outcomes associated with the domino procedure involving HLT are acceptable in the short and intermediate term; however, only small single-center studies have investigated outcomes. Pooled data on long-term potential consequences of HLT and associated domino operations are limited. To address the gap on the topic, we conducted a systematic review to investigate the indications and longterm outcomes associated with the domino procedure.

\section{Methods}

\section{Literature search strategy}

In December 2018, an electronic search was performed to identify all prospective and retrospective studies on the domino procedure in the English literature. Databases including Ovid Medline, Web of Science, Scopus, Cochrane Central Register of Controlled Trials (CCRT), and Cumulative Index of Nursing and Allied Health (CINAHL). To achieve the maximum sensitivity of the search strategy, the following combined terms were used: "domino" or "heart-lung transplant" or "cardiopulmonary transplant". The reference lists of all eligible studies were reviewed for further identification of potentially relevant studies and assessed using the inclusion and exclusion criteria. Utilizing the Newcastle-Ottawa Scale (NOS) scoring system, a risk of bias assessment was performed for the identified studies as recommended by the Cochrane Collaboration and found in Table S1. In addition, a GRADE assessment was applied to evaluate outcomes. Our overall search strategy is depicted in Tables $S 2, S 3, S 4, S 5$.

\section{Study criteria}

Eligible studies included all prospective and retrospective studies on patients who underwent HLT during which a domino heart was used in a subsequent HT procedure. When institutions published duplicate studies with accumulating numbers of patients or increased lengths of follow-up, only the most complete reports were included for quantitative assessment with no overlapping time 
intervals. We excluded studies on patients less than 18 years of age, those not involving human subjects, and those not written in the English language. Case reports, editorials, and reviews were also excluded.

\section{Data extraction}

All available data were extracted from text, tables, and figures in each identified article (MA, AD, EM). Data were reexamined for any discrepancies and any vague information was resolved via discussion to reach a consensus.

\section{Statistical analysis}

For statistical analysis, methodologies reported by Phan et al. were implemented (9). For dichotomous variables, a meta-analysis of proportions with logit transformation was conducted for the available main perioperative and postoperative variables. Continuous data were combined via meta-analysis with random-effects model. Heterogeneity was evaluated using Cochran $\mathrm{Q}$ and $\mathrm{I}^{2}$ test. R software, version 3.6.1, (R Foundation for Statistical Computing; Vienna, Austria) was used for all data analysis and visualization. The meta-analysis was performed using meta package for R. P values $<0.05$ were considered statistically significant.

\section{Results}

\section{Study characteristics}

Overall, 5,251 distinct records were identified in the literature search. Eligible studies included all prospective and retrospective studies on patients who underwent HLT during which a domino heart was used in a subsequent HT procedure. The search encompassed 3,567 articles following the removal of duplicates. Articles that did not include patients who underwent HLT with a subsequent domino HT were excluded. As a result of this, 3,558 articles were excluded. Of the remaining nine articles, one full-text article was excluded as it did not have specific follow up and outcomes data necessary for our study. This resulted in eight full-text articles that met our inclusion and exclusion criteria for statistical analysis (5,10-16). A PRISMA flow diagram depicting the overall search strategy is shown in Figure 1 and a detailed description of the studies included in the analysis is reported in Table 1. All studies included were single-center retrospective studies and case series.

\section{Baseline characteristics}

HLT indications included cystic fibrosis in 58\% (95\% CI: $27-84 \%$ ) of recipients, $\mathrm{PPH}$ in $17 \%$ (95\% CI: $12-24 \%$ ), bronchiectasis in 5\% (95\% CI: 3-10\%), emphysema in 5\% (95\% CI: $0-45 \%$ ), and Eisenmenger's syndrome in 4\% (95\% CI: 2-8\%). HT indications included ischemic heart disease in 40\% (95\% CI: 33-47\%), non-ischemic disease in 39\% (95\% CI: $25-56 \%$ ), and re-transplantation in $10 \%$ (95\% CI: 1-59\%). Details on baseline characteristics are outlined in Table 2.

\section{Pre-operative variables}

The pooled mean pulmonary vascular resistance (PVR) in HT recipients was 3.05 Woods units (95\% CI: $0.14-$ 5.95). Overall, HT operative characteristics included preoperative mechanical support in $26 \%$ (95\% CI: $16-40 \%$ ), a mean cardiopulmonary bypass time of 100 minutes $(95 \%$ CI: 68-131), and an ischemic time of 78 (95\% CI: 66-90) minutes. Details on the HT operative characteristics are found in Table 3. Three of the most common post-operative complications included CMV infections in 49\% (95\% CI: $10-89 \%$ ), acute rejection in $38 \%$ (95\% CI: $21-59 \%$ ) and herpes pharyngitis in 20\% (95\% CI: 7-47\%). Details on HT post-operative complications are shown in Table 3.

\section{Survival and outcomes}

The overall mortality in the HLT group was 28\% (95\% CI: $18-41 \%)$ with an average follow-up of 15.68 months (95\% CI: $0.82-30.54$ ), and 35\% (95\% CI: $17-58 \%$ ) in the HT group at an average follow-up of 37.26 months (95\% CI: $6.68-67.84 \%$ ). Long-term survival of the HLT and HT groups is shown in Figure 2 and Figure 3 respectively. Freedom from rejection in HT was $94 \%$ (95\% CI: $75-99 \%$ ) at 1 month, $77 \%$ (95\% CI: 30-96\%) at 6 months, and $41 \%(95 \%$ CI: $33-50 \%)$ at 1 year. A subgroup comparison between HLT and HT recipients demonstrated a significant difference in the age [mean HLT age, 26.71 years (95\% CI: 21.26-32.16) vs. mean HT age, 40.42 years (95\% CI: $32.24-48.59), \mathrm{P}<0.01]$ and a trend towards significance in sex distribution $[45 \%$ males in HLT group (95\% CI: 29-63\%), vs. 68\% males in the HT group]. Details on operative and post-operative outcomes for the HLT and HT groups are shown in Table 4 and Table 5 respectively. 

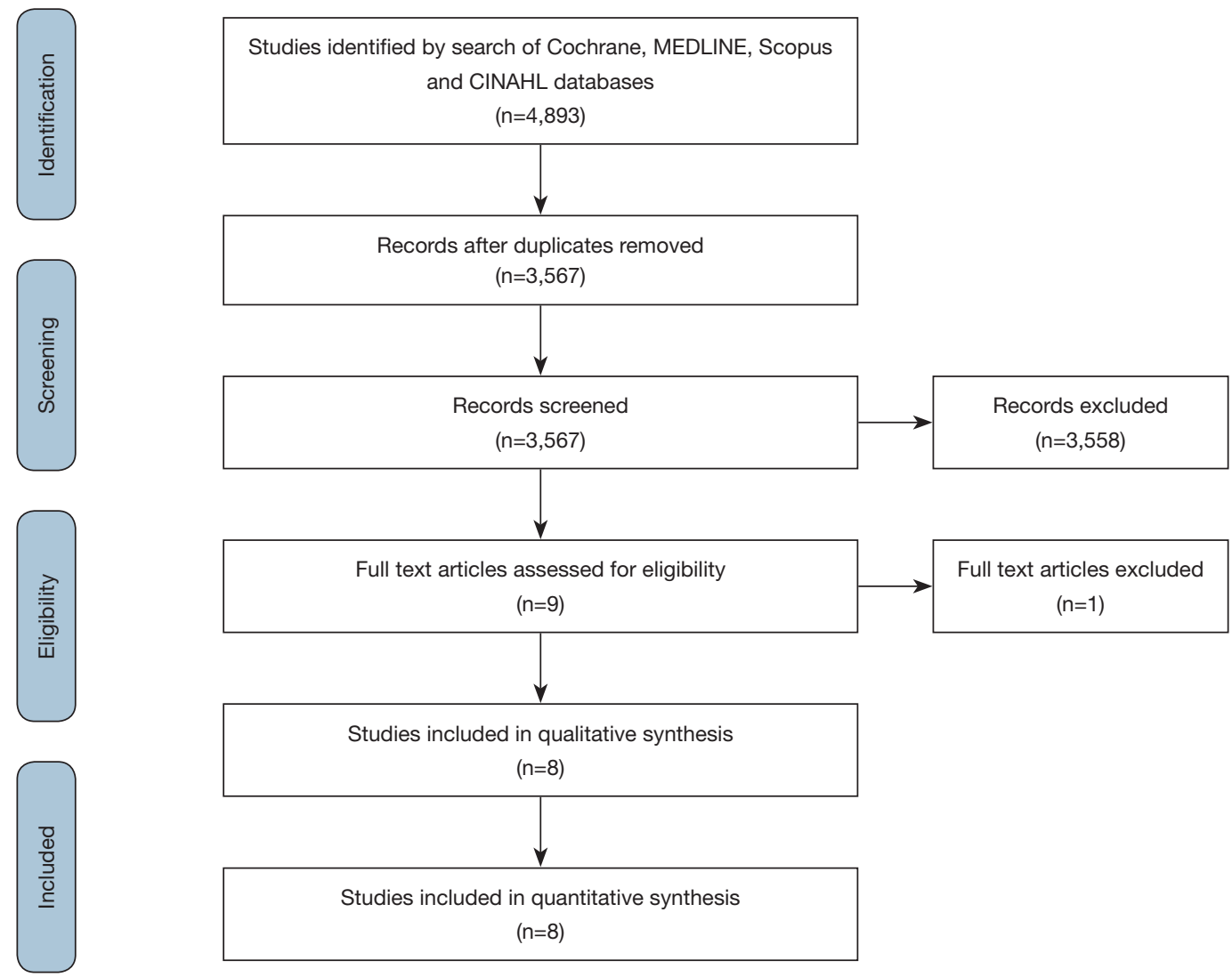

Figure 1 PRISMA schematic diagram of the search strategy. PRISMA, Preferred Reporting Items for Systematic Reviews and MetaAnalysis.

\section{Heart transplant $v s$. heart-lung transplant comparison for age, sex and length of hospital stay}

When the HT and HLT groups were compared for age, sex and length of hospital stay, there was no significant difference between the groups in terms of sex, length of hospital stay; however, a difference was noted when the ages were compared between groups. This comparison can be found in Table 6.

\section{Discussion}

In this systematic review, we found that overall mortality in the HLT group was $28 \%$ (95\% CI: $18-41 \%$ ) at an average follow-up of 15.68 months (95\% CI: $0.82-30.5$ ), and 35\% in the HT group (domino recipient) at an average follow-up of 37.26 months. These relatively low mortality rates were associated with an acceptably low complication and rejection rate among the domino patient. As mentioned in previous reports, one major benefit of the domino procedure is that operative planning may be set in place to allow for surgical planning and strategic patient management such echocardiography and other necessary imaging assessments (5). Thus, the pre-operative planning may also include any necessary valve repairs in potential domino donors (i.e., congenital heart defects associated with Eisenmenger's syndrome), such that the viability of domino hearts may be improved (5). Despite this possibility, the increase in domino hearts via this method would still be limited given patient-specific factors. Human leukocyte antigen (HLA) matching and cytotoxic antibody assessments can also be performed adequately (5). Other benefits may be associated with right ventricular hypertrophy resulting from the domino donor's lung disease. The hearts of domino donors are thought be preconditioned to increased pulmonary pressures and thereby provide a more suitable allograft for domino recipients with pre-existing, high PVR (5). In this scenario, the heart is seen to be already suited to fit the donor's pathophysiological conditions. 


\begin{tabular}{|c|c|c|c|c|c|c|}
\hline $\begin{array}{l}\text { Raffa } \\
\text { et al. (16) }\end{array}$ & $\begin{array}{l}\text { Domino Heart Transplantation: Long- } \\
\text { Term Outcome of Recipients and Their } \\
\text { Living Donors: Single Center Experience }\end{array}$ & 2010 & $\begin{array}{l}\text { Transplantation } \\
\text { Proceedings }\end{array}$ & 1991-1996 & Retrospective & 10 \\
\hline $\begin{array}{l}\text { Cochrane } \\
\text { et al. (5) }\end{array}$ & $\begin{array}{l}\text { The "domino-donor" operation in heart } \\
\text { and lung transplantation }\end{array}$ & 1991 & $\begin{array}{l}\text { The Medical Journal } \\
\text { of Australia }\end{array}$ & 1990-1991 & Retrospective & 5 \\
\hline $\begin{array}{l}\text { Cavarocchi } \\
\text { et al. (13) }\end{array}$ & $\begin{array}{l}\text { Heart/Heart-Lung Transplantation The } \\
\text { Domino Procedure }\end{array}$ & 1989 & $\begin{array}{l}\text { Annals of Thoracic } \\
\text { Surgery }\end{array}$ & $1987-1988$ & Retrospective & 3 \\
\hline $\begin{array}{l}\text { Kells } \\
\text { et al. (14) }\end{array}$ & $\begin{array}{l}\text { Cardiac function after domino-donor } \\
\text { heart transplantation }\end{array}$ & 1992 & $\begin{array}{l}\text { The American } \\
\text { Journal of Cardiology }\end{array}$ & 1988-1989 & Retrospective & 7 \\
\hline $\begin{array}{l}\text { Rosado } \\
\text { et al. (15) }\end{array}$ & $\begin{array}{l}\text { Sinoatrial node dysfunction in } \\
\text { recipients of domino heart transplants: } \\
\text { Complication of a surgical harvesting } \\
\text { technique }\end{array}$ & 1992 & $\begin{array}{l}\text { The Journal of Heart } \\
\text { and Lung Transplant }\end{array}$ & 1989-1991 & Retrospective & 6 \\
\hline
\end{tabular}

Matching the donor and recipient this way may reduce risks of early right heart failure post transplantation.

The increase in domino heart compatibility related to pulmonary pressure matching between donor and recipient can be contrasted with the orthotopic heart transplant (OHT). For OHT, one study suggested that increased right ventricular afterload and associated right ventricular dysfunction are considered important factors influencing outcome after HT (17). In fact, it has been estimated that pulmonary hypertension might account for up to $50 \%$ of cardiac allograft failure and almost $20 \%$ of deaths in the early post-operative period (17). This contrasts with the domino HLT procedure as the donor heart has been subjected to "preconditioning" due to pulmonary hypertension, theoretically decreasing the rate of acute donor right heart failure in recipients with pre-existing PVR elevation (14).

Currently, donor heart selection criteria for OHT are focused on factors such as age, donor heart function, and donor-recipient compatibility factors such as body size and weight matching, and ischemic times (18); the donor's right ventricular function is not matched with the recipient's pulmonary vascular parameters. This may be something to consider for future selection criteria for OHT.

Another advantage of domino donor lies in the pathophysiology of using a live donor. Most HLT recipients in this analysis (domino donors) were live patients with cystic fibrosis, primary pulmonary hypertension $\mathrm{PPH}$, bronchiectasis and Eisenmenger's syndrome. In contrast to live donors, brain dead donors experience a rise in intracranial pressure (ICP) following death, which results in an increase in catecholamines (catecholamine storm) that can have negative effects on the cardiovascular system including ischemic injury and inflammation (19-21). In addition, brain dead donors often require extensive care of the body post brain death, such as continued mechanical ventilation and life support measures, which may extend over several hours or even days (17).

Over the past 20 years, there has been a movement away from performing combined heart and lung transplantation 
Table 2 Baseline characteristics and indications for heart-lung transplant and heart transplant recipients

\begin{tabular}{|c|c|c|c|c|c|}
\hline Variable & Pooled value $[95 \% \mathrm{Cl}]$ & No. of studies & Event & Total & Heterogeneity $\left(I^{2} \%\right)$ \\
\hline Age (years) & $26.71[21.26-32.16]$ & 5 & & 25 & 0 \\
\hline Sex, male (\%) & $47[38-57]$ & 6 & 85 & 183 & 10 \\
\hline Cystic fibrosis (\%) & 58 [27-84] & 6 & 125 & 183 & $76^{*}$ \\
\hline Emphysema (\%) & $5[0-45]$ & 2 & 3 & 136 & $77^{*}$ \\
\hline Bronchiectasis (\%) & $5[3-10]$ & 3 & 8 & 163 & 0 \\
\hline Eisenmenger's syndrome (\%) & $4[2-8]$ & 2 & 6 & 156 & 0 \\
\hline \multicolumn{6}{|l|}{ HT baseline characteristics and indications } \\
\hline Ischemic (\%) & $40[33-47]$ & 5 & 69 & 173 & 0 \\
\hline Non-ischemic (\%) & 39 [25-56] & 6 & 68 & 176 & 44 \\
\hline Re-transplant (\%) & $10[1-59]$ & 3 & 9 & 161 & $90^{*}$ \\
\hline \multicolumn{6}{|l|}{ Type of HT } \\
\hline Orthotopic transplant (\%) & 89 [82-93] & 4 & 133 & 149 & 0 \\
\hline Heterotopic transplant (\%) & $8[4-14]$ & 4 & 10 & 149 & 0 \\
\hline
\end{tabular}

*, heterogeneity $\mathrm{P}<0.05$ (significant data heterogeneity present).

Table 3 Heart transplant recipient operative characteristics and post-operative complications

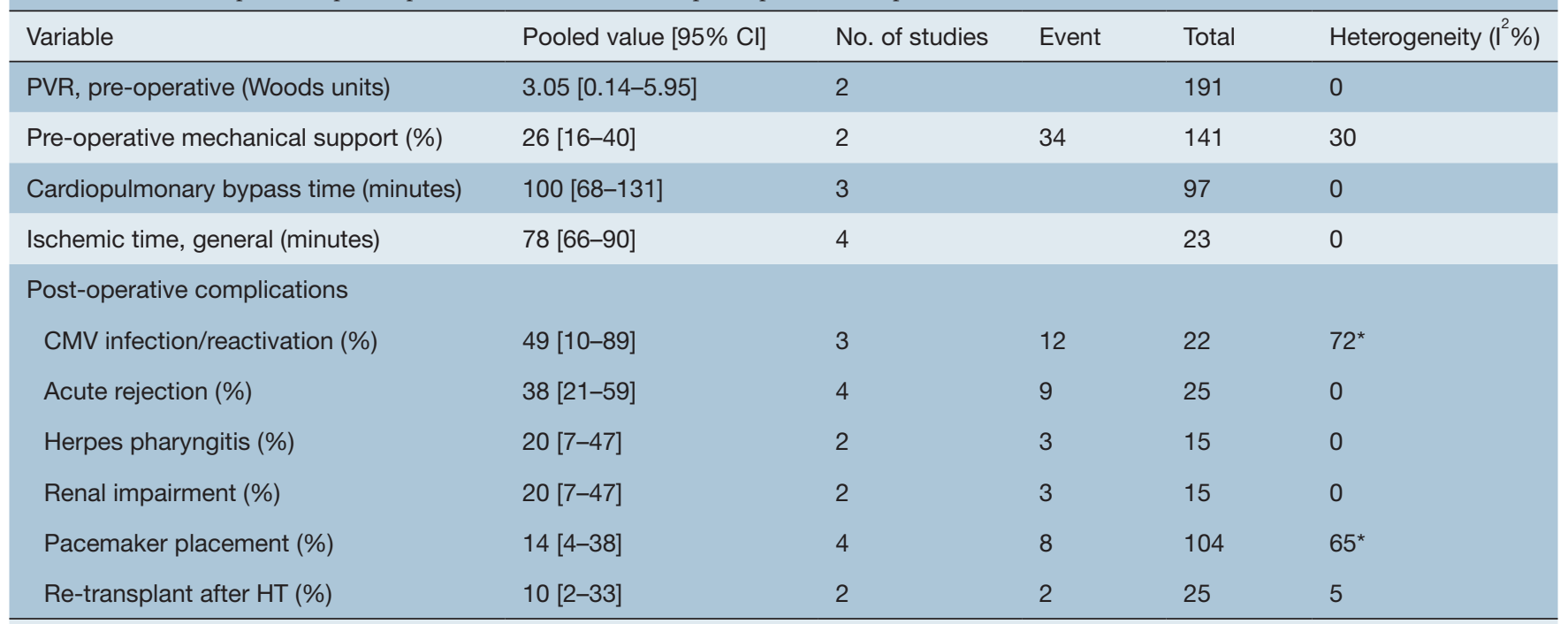

*, heterogeneity $\mathrm{P}<0.05$ (significant data heterogeneity present). 


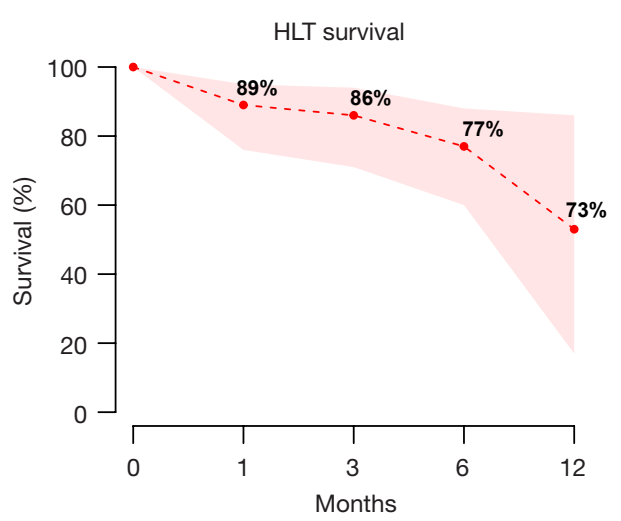

Figure 2 Long-term heart-lung transplant (HLT) survival curve for the domino procedure.

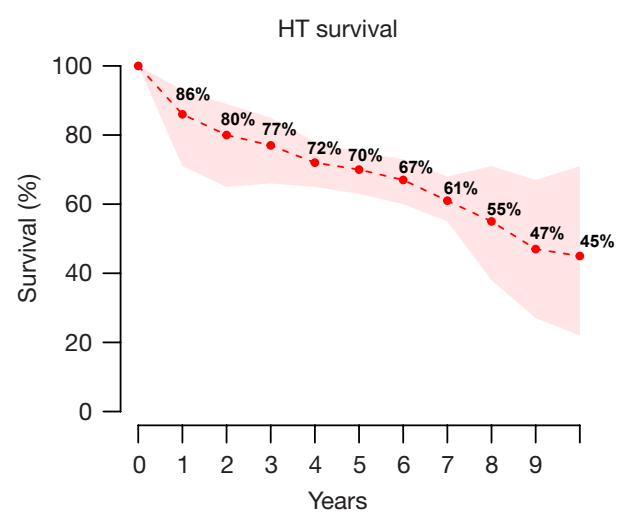

Figure 3 Long-term heart transplant (HT) survival curve for the domino procedure.

\begin{tabular}{llllll} 
Table 4 Heart-lung transplant recipient outcomes & & & \\
\hline Variable & Pooled value [95\% Cl] & No. of studies & Events & Total & Heterogeneity $\left(I^{2} \%\right)$ \\
\hline CMV reactivation & $32[16-54]$ & 3 & 10 & 33 & 14 \\
Follow-up (months) & $15.68[0.82-30.54]$ & 4 & 42 & 52 \\
Mortality, overall (\%) & $28[18-41]$ & 4 & 5 & 60 & 0 \\
Mortality, 30 days (\%) & $11[5-23]$ & 4 & 22 & 60 & 0 \\
Survival, 1 year (\%) & $73[55-86]$ & 2 & 30 & 0 \\
\hline
\end{tabular}

\begin{tabular}{|c|c|c|c|c|c|}
\hline Variable & Pooled value $[95 \% \mathrm{Cl}]$ & No. of studies & Event & Total & Heterogeneity $\left(I^{2} \%\right)$ \\
\hline Follow-up (months) & 37.26 [6.68-67.84] & 4 & & 230 & $88^{*}$ \\
\hline Mortality, overall (\%) & 35 [17-58] & 8 & 118 & 263 & $84^{*}$ \\
\hline Mortality, 30 days (\%) & 12 [8-18] & 8 & 27 & 263 & 11 \\
\hline \multicolumn{6}{|l|}{ Freedom from rejection } \\
\hline 1 month (\%) & 94 [75-99] & 3 & 29 & 29 & 0 \\
\hline 6 months (\%) & 77 [30-96] & 3 & 25 & 29 & 61 \\
\hline 1 year $(\%)$ & $41[33-50]$ & 2 & 55 & 134 & 0 \\
\hline Infection (\%) & $7[1-42]$ & 2 & 5 & 141 & $83^{*}$ \\
\hline Malignancy (\%) & $4[0-58]$ & 2 & 3 & 141 & $87^{\star}$ \\
\hline Multi-organ failure (\%) & $7[1-28]$ & 2 & 7 & 151 & $78^{\star}$ \\
\hline Renal failure (\%) & $2[1-7]$ & 2 & 3 & 151 & 0 \\
\hline
\end{tabular}




\begin{tabular}{|c|c|c|c|c|c|c|c|c|c|c|c|}
\hline Variable & $\begin{array}{l}\text { Pooled value } \\
{[95 \% \mathrm{Cl}]}\end{array}$ & $\begin{array}{l}\text { No. of } \\
\text { studies }\end{array}$ & Event & Total & $\begin{array}{l}\text { Heterogeneity } \\
\left(I^{2} \%\right)\end{array}$ & $\begin{array}{l}\text { Pooled value } \\
{[95 \% \mathrm{Cl}]}\end{array}$ & $\begin{array}{l}\text { No. of } \\
\text { studies }\end{array}$ & Event & Total & $\begin{array}{l}\text { Heterogeneity } \\
\left(I^{2} \%\right)\end{array}$ & $\begin{array}{l}\mathrm{P} \\
\text { value }\end{array}$ \\
\hline $\begin{array}{l}\text { Age } \\
\text { (years) }\end{array}$ & $\begin{array}{l}26.71 \\
{[21.26-32.16]}\end{array}$ & 5 & & 25 & 0 & $\begin{array}{l}40.42 \\
{[32.24-48.59]}\end{array}$ & 6 & & 105 & 10 & $<0.01$ \\
\hline $\begin{array}{l}\text { Hospital } \\
\text { stay (days) }\end{array}$ & 31 [9-52] & 2 & & 15 & 0 & 16 [5-28] & 2 & & 15 & 21 & 0.24 \\
\hline
\end{tabular}

and a move toward single and DLT; one reason is because there is an assumption that those with right heart failure and end-stage lung disease may recover from a cardiovascular standpoint and therefore the en bloc heart-lung procedure is not necessary (22). There continues to be some uncertainty surrounding the move away from HLT as comparative studies like that of Ganesh et al. found that after adjusting for comorbidities, heart-lung and BSSLT achieved a similar outcome (4). Currently, the most common indications for HLT are associated with congenital heart defects such as Eisenmenger's syndrome. However, 20-30 years ago, most domino donors were patients with cystic fibrosis (CF). Another reason en bloc procedures have largely been replaced by DLT and BSSLT is due to organ shortages rather than differences in outcomes (6). Proponents argue that the use of domino HT ameliorated the impact of problems associated with HLT allocation and its effects on total organ availability at that time (6). As HLT and DLT outcomes are relatively comparable, it may be argued that perhaps a patient specific strategy for HLT and subsequent organ allocation management is warranted. Even though HLT may no longer be necessary in patients with CF, the congenital cardiac defect population may emerge as a new pool of HLT domino donors with the development of new surgical techniques to treat these cardiac defects. While the move away from HLT has decreased the number of domino donor heart procedures performed, re-considering this procedure in select patients may be a resourceful strategy to help address organ shortage problems and long waitlists.

\section{Limitations}

\section{Quality of evidence}

In our GRADE assessment of the level of evidence, we found that the outcomes were of moderate quality mostly due to the risk of bias associated with retrospective studies. However, since our confidence intervals were relatively narrow for most of the variables assessed, this may have increased the quality of evidence to a higher level.

This review has some key limitations and must be interpreted with care. Differences existed in patient selection and there was a relative paucity of literature published on this topic. We were unable to do a quantitative comparison of HLT $v s$. HT rejection rate since a lot of the studies analyzed did not have comparative arms for statistical analysis. Differences were also noted among the studies in terms of patient and donor selection, study design, center experiences, immunosuppressive regimens used, techniques, and clinical management of transplant patients. We acknowledge that this heterogeneity in study population is a fundamental limitation that cannot be addressed due to the inability to extract sufficient detail from the pooled data.

\section{Conclusions}

The domino heart procedure following HLT is a viable and safe strategy that has the unique advantage of using the highly conditioned hearts from idiopathic pulmonary hypertensive recipients for those with prohibitive pulmonary hypertension in need of a heart transplant.

\section{Acknowledgments}

None.

\section{Footnote}

Conflicts of Interest: The authors have no conflicts of interest to declare. 


\section{References}

1. Available online: https://unos.org/data/transplant-trends/

2. Smith JA, Roberts M, Mcneil K, et al. Excellent outcome of cardiac transplantation using domino donor hearts. Eur J Cardiothorac Surg 1996;10:628-33.

3. Tong MZ, Johnston DR, Pettersson GB. The Role of Bronchial Artery Revascularization in Lung Transplantation. Thorac Surg Clin 2015;25:77-85.

4. Ganesh JS. Outcome of heart-lung and bilateral sequential lung transplantation for cystic fibrosis: a UK national study. Eur Respir J 2005;25:964-9.

5. Cochrane AD, Smith JA, Esmore DS. The "dominodonor" operation in heart and lung transplantation. Med J Aust 1991;155:589-93.

6. Hill C, Maxwell B, Boulate D, et al. Heart-lung vs. double-lung transplantation for idiopathic pulmonary arterial hypertension. Clin Transplant 2015;29:1067-75.

7. Brouckaert J, Verleden SE, Verbelen T, et al. Doublelung versus heart-lung transplantation for precapillary pulmonary arterial hypertension: a 24-year single-center retrospective study. Transpl Int 2019;32:717-29.

8. Astor TL, Galantowicz M, Phillips A, et al. Domino Heart Transplantation Involving Infants. Am J Transplant 2007;7:2626-9.

9. Phan K, Tian DH, Cao C, et al. Systematic review and meta-analysis: techniques and a guide for the academic surgeon. Ann Cardiothorac Surg 2015;4:112-22.

10. Yacoub MH, Banner NR, Khaghani A, et al. Heart-lung transplantation for cystic fibrosis and subsequent domino heart transplantation. J Heart Transplant 1990;9:459-66; discussion 466-7.

11. Anyanwu AC, Banner NR, Radley-Smith R, et al. Longterm results of cardiac transplantation from live donors: the domino heart transplant. J Heart Lung Transplant 2002;21:971-5.

12. Luckraz H, Charman SC, Parameshwar J, et al. Are non-

Cite this article as: Maynes EJ, O'Malley TJ, Austin MA, Deb AK, Choi JH, Weber MP, Khaghani A, Massey HT, Daly RC, Tchantchaleishvili V. Domino heart transplant following heartlung transplantation: a systematic review and meta-analysis. Ann Cardiothorac Surg 2020;9(1):20-28. doi: 10.21037/ acs.2019.12.02 brain stem-dead cardiac donors acceptable donors? J Heart Lung Transplant. 2004:23:330-3.

13. Cavarocchi NC, Badellino M. Heart/heart-lung transplantation the domino procedure. Ann Thorac Surg 1989;48:130-3.

14. Kells CM, Marshall S, Kramer M, et al. Cardiac function after domino-donor heart transplantation. Am J Cardiol 1992;69:113-6.

15. Rosado LJ, Huston CL, Sethi GK, et al. Sinoatrial node dysfunction in recipients of domino heart transplants: complication of a surgical harvesting technique. J Heart Lung Transplant 1992;11:1078-81.

16. Raffa GM, Pellegrini C, Viganò M. Domino Heart Transplantation: Long-Term Outcome of Recipients and Their Living Donors: Single Center Experience. Transplant Proc 2010;42:3688-93.

17. Bolliger D, Bouchez S, Mauermann E. Re-examining Factors Associated With Mortality After Heart Transplantation: A Focus on Recipient Age and Relative Pulmonary Hypertension. J Cardiothorac Vasc Anesth 2018;32:41-3.

18. Kilic A, Emani S, Sai-Sudhakar CB, et al. Donor selection in heart transplantation. J Thorac Dis 2014;6:1097-104.

19. Anwar ASMT, Lee J. Medical Management of Brain-Dead Organ Donors. Acute Crit Care 2019;34:14-29.

20. Dupuis S, Amiel JA, Desgroseilliers M, et al. Corticosteroids in the management of brain-dead potential organ donors: a systematic review. Br J Anaesth 2014;113:346-59.

21. Amado JA, López-Espadas F, Vázquez-Barquero A, et al. Blood levels of cytokines in brain-dead patients: Relationship with circulating hormones and acute-phase reactants. Metabolism 1995;44:812-6.

22. Hales CM, Carroll MD, Fryar CD, et al. Prevalence of Obesity Among Adults and Youth: United States, 20152016. NCHS Data Brief 2017;(288):1-8. 


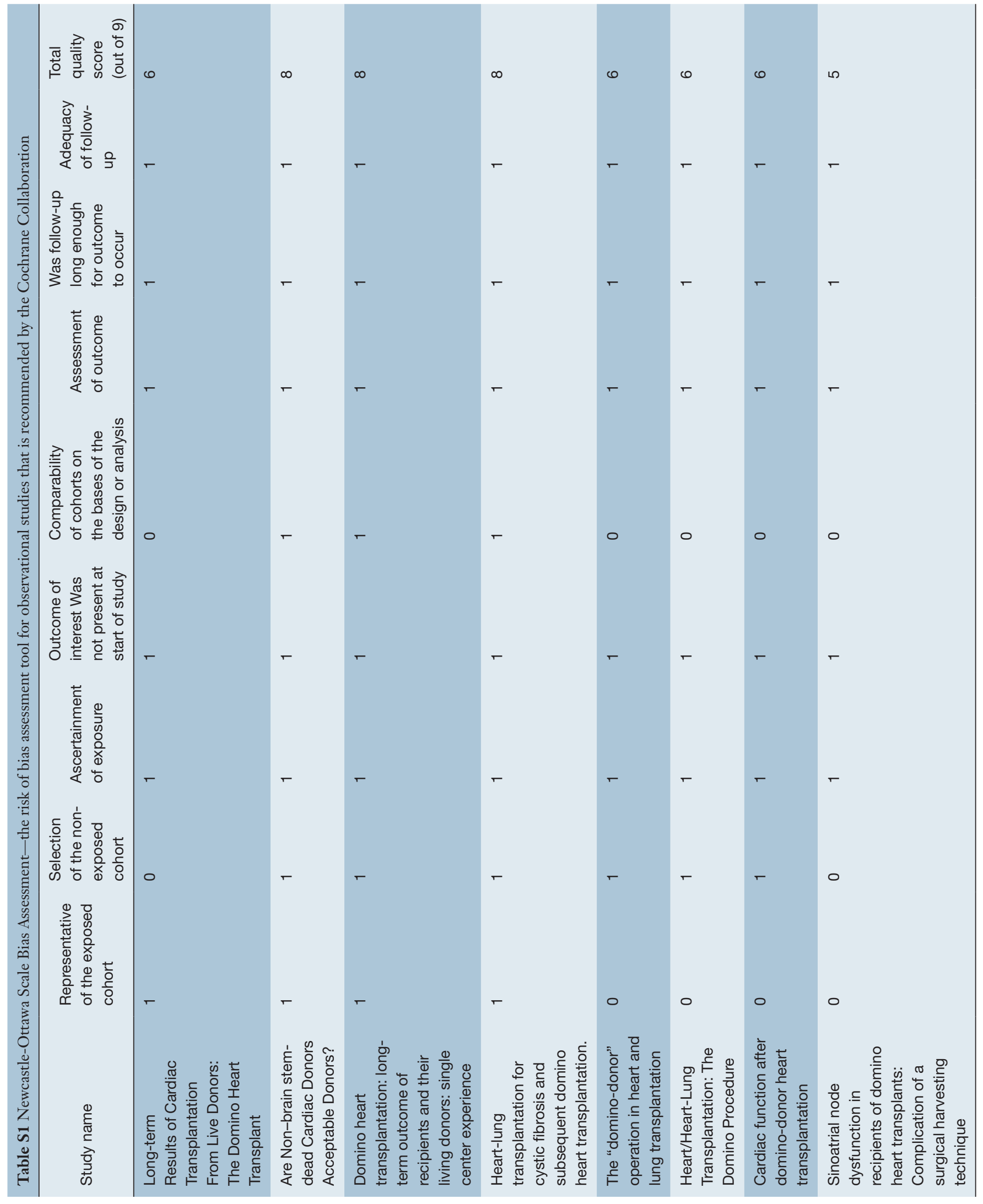


Table S2 Scopus search strategy (Date searched: December 5, 2019)

\begin{tabular}{lll}
\hline & Scopus (advanced) & Search results \\
\hline 1 & TITLE-ABS-KEY(“heart-lung & 2,602 \\
& $\begin{array}{l}\text { transplant"” OR "cardiopulmonary } \\
\text { transplant" and "domino*”) }\end{array}$ \\
\hline
\end{tabular}

Table S3 CCTR search strategy (Date searched: December 5, 2019)

CCTR Search results

1 "heart-lung transplant" OR
"cardiopulmonary transplant" OR
"domino"

Table S4 CINAHL search strategy (Date searched: December 5, 2019)

CINAHL Search results

\begin{tabular}{|c|c|c|}
\hline 1 & $\begin{array}{l}\text { (MH "heart-lung transplant*") OR (MH } \\
\text { "cardiopulmonary transplant") } \text { OR (MH } \\
\text { "domino") }\end{array}$ & 364 \\
\hline
\end{tabular}

Table S5 Medline search strategy (Date searched: December 5, 2019)

\begin{tabular}{lll}
\hline & MEDLINE (Ovid SP) (Basic) & Search results \\
\hline 1 & Heart-lung transplant ${ }^{\star}$ & 1,967 \\
\hline 2 & Cardiopulmonary transplant* $^{\star}$ & 23 \\
\hline 3 & Domino* $^{*}$ & 3,137 \\
4 & 1 or 2 or 3 & 5,118 \\
\hline 25 & Limit 4 to English language and humans & 2,281 \\
\hline
\end{tabular}

